\title{
Pulmonary Infarction
}

National Cancer Institute

\section{Source}

National Cancer Institute. Pulmonary Infarction. NCI Thesaurus. Code C50714.

Localized necrosis of lung tissue caused by obstruction of the arterial blood supply, most often due to pulmonary embolism. 